\title{
Reframing the global poverty and inequality narrative in development education through the lens of intersectionality
}

\author{
Son Gyoh* - Irish Development Education Association (IDEA), Ireland
}

\begin{abstract}
The effort to promote interdisciplinary research in development and global education risks the erosion of its core values by more theoretically established fields of development. This becomes urgent when little research attention is given to strengthening the theoretical foundation of core concepts and themes, such as global poverty and inequality, that are grounded in knowledge from field experience. This article responds to the influence of neoclassical literature about poverty and spatial inequality that propagates a discourse shift from poor countries to poor people. Intersectionality is explored as a paradigm that can reconcile this new thinking with the social justice pedagogy of development education and that enables an understanding of the asymmetries in current patterns of poverty and spatial inequality.
\end{abstract}

Keywords: spatial inequality; poverty; intersectionality; interdependence; globalization; core-periphery

\section{Introduction}

The profound effects of globalization and technological revolution on wealth creation, and resource allocation and distribution within and across economies have led to renewed debates about regional development and spatial inequality (Stiglitz, 2012; Piketty, 2014). The continued framing of global poverty and inequality in terms of binaries of 'poor' and 'rich' countries has been argued to be inadequate for explaining spatial inequality in the era of globalization, where a higher number of income-poor now live in middle-income countries (Sumner et al., 2012; Kanbur and Sumner, 2011). While there is acknowledgement of the spatiality of inequality across industrial and developing economies, the argument has been embraced in development and global education discourse without critical engagement with the nuanced distinction between 'inequality' and 'poverty', and theories that underpin its social justice pedagogy (see, for example, Konttinen and Vihriälä, 2014).

This article emphasizes the importance of broadening the scope of development and global education engagement with current thinking on spatial inequality, as well as understanding how poverty and inequality manifest along relationships of power imbalances. The term 'development and global education' is used in this article as an umbrella concept that encompasses critical approaches to global education. I adopt definitions and assumptions from development education, a tradition of global education that is strongly influenced by critical and emancipatory pedagogy. I draw attention to how the uncritical inauguration of neoclassical theories about spatial inequality in development and global education undermines its concern with the 
disproportionate concentration of poverty in less industrialized economies. I argue that while the less developed countries and industrialized economies may not function in binary opposition, they interact in a fashion that reproduces and disproportionately concentrates poverty and inequality along economic geographies of countries on the margins of a globalized economy.

I propose that theories of spatial inequality are frequently based on national surveys of household income, wealth distribution and foreign investment, with little attention to the international dimension. Although these studies recognize the influence of factors such as location, agglomeration, borders and trade agreements, their implications for defining how countries are integrated into the global economy have not received similar attention (Stiglitz, 2012; Piketty, 2014; Berry et al., 2014). This article proposes intersectionality as an analytical paradigm that can contribute to exploring and gaining critical understanding of, the complex interaction and intersection of structures and processes that reproduce and concentrate poverty and inequality in a particular global pattern.

Intersectionality complements the use of post-colonial theory in development and global education, particularly in its proposition about how privilege, oppression, exclusion and inclusion interact and intersect with structures of power (Glenn, 2002; McCall, 2005). Such a paradigm would enable a basic familiarity with theories about spatial inequality and also contribute to reconceptualizing the theories of coreperiphery dependency that underline the social justice pedagogy of development and global education.

While this article draws on the propositions of post-colonial literature about power imbalances between the 'occident' North and 'subaltern' South, its primary concern is to highlight the importance of understanding how structures and processes of globalization interact in reproducing the current pattern of global interdependence. The concept of intersectionality is therefore explored as both a paradigm and methodological approach that can enable the interrogation and application of theoretical propositions from related disciplines, such as regional inequality and economic geography. Addressing current unjust forms of interdependence requires understanding the interaction and intersection of processes that manifest in the spatial but disproportionate concentration of poverty in less industrialized economies (Bourn, 2015).

Following this introduction, the methodological considerations and theoretical influences of the article are described. This is followed by a brief outline of the specific themes and the context in which the research problem is framed. The concept of intersectionality is introduced and explored as an analytical paradigm that can enable a critical understanding of inequality and spatiality as components of inequality in an interdependent world (Stiglitz, 2012; Wei, 2015; Kanbur and Sumner, 2011). The system approach to intersectionality is identified and articulated as a paradigm that can contribute to understanding the complex intersections between local and global dynamics and the international dimensions of spatial inequality.

In later sections of the article, the core-periphery binary is revisited and discussed within the context of spatial inequality and patterns in the distribution of multidimensional poverty in an interdependent world. Using concrete examples, I consider the limitations of gross domestic income (GDI) per capita for discussing trends in the number of people living in poverty in less developed economies. 


\section{Methodological considerations}

Constructing a methodology for analysing institutional processes is theoretically challenging, particularly when the research problem concerns the interpretation of concepts that describe dimensions of economic and social experience. Considering that this article does not include primary data, the methodology is constructed as a strategy for revisiting and unpacking the changing boundaries and meanings of concepts of development and global education subsumed in interdisciplinary discourses about poverty and global inequality. It is designed specifically to revisit and reposition the core-periphery narrative of dependency that underpins the social justice pedagogy of development and global education in the context of the instabilities proposed in related fields of regional development and spatial inequality (see, for example, Piketty, 2014; Li and Wei, 2010; Liao and Wei, 2015). This will contribute to a deeper understanding of the dynamics of poverty and spatial inequality within countries and across geographical regions.

The methodology starts by reconstructing the dependency core-periphery relationship between 'poor' and 'rich' countries as asymmetrical and interdependent rather than as binary opposites (Tausch, 2010; Sekhri, 2009). This explains the globalization of the structural processes, where economies and societies are more connected than ever before. The methodology draws on the literature of regional inequality and economic geography that analyses factors that interact to collectively generate income disparity and spatial inequality in developing countries. Replication logic is applied in considering the pattern in which these dynamics occur across countries that share similar historical experiences (Denzin and Lincoln, 2000) and how spatial inequality manifests along the clustering of economic activity around industrial and/or urban regions (Abdulai, 2014). The methodology also strengthens the utility of post-colonial theory in emphasizing the primacy of power relations and in highlighting how inequality may not always explain the causes or levels of poverty.

The methodology also serves as a primer for exploring the mode of intersectionality that is most suited to analysing the interaction between institutions, power and processes in diverse social and geographical locations. Although no attempt is made to perform a systematic application of intersectionality in this article, the methodology sets the stage for the questioning of assumptions and reconceptualizing the core-periphery/Global North-Global South dichotomy as social constructions, rather than as geographical expressions.

\section{Global poverty and spatial inequality: A development/ global education perspective}

The 2002 Maastricht Declaration defines global education as 'education that opens people's eyes and minds to the realities of the world and awakens them to bring about a world of greater justice, equity and human rights for all' (Hartmeyer and Wegimont, 2016: 10). It is therefore an educational endeavour that emerged in industrialized highincome countries to increase knowledge about development issues and also to garner public support for national budgets for international development (Ishii, 2003; Bourn, 2015). Within this definition, the broad themes of justice and equality are normative values that underpin the social justice pedagogy of development education, a tradition of global education with strong roots in practice, theories of transformative learning and public deliberation (Bourn, 2015). The models for measuring spatial inequality are complex and sometimes dense in equations and therefore require that 
development and global education develop resilient analytical tools that are accessible to autonomous learners.

The discourse of development and global education has historically been constructed on understanding and challenging multidimensional inequalities and the perceived unjust relationship between the high-income industrialized economies and less industrialized low-income countries (Bourn, 2015). Quite often, the debates have focused on imbalances in power relations and the role of citizens in reversing the consumption patterns between the rich and the majority poor countries. This valuesbased vision often presents a challenge, not only in understanding interdependence beyond the division between 'rich' and 'poor' countries, but also because it may detract from interrogating the processes by which inequality is produced and spatially distributed in the era of the globalization of production. Kanbur and Venables (2005: 11) describe spatial inequality as 'inequality in economic and social indicators of wellbeing across geographical units within a country'. The indicators used for measuring spatial inequality are therefore within the boundaries of a national economy, and are used as a proxy for analysing the international dimension, with little attention paid to patterns of global concentration.

The stated commitment of the United Nations Sustainable Development Goals 2030 agenda to mobilize the means to end extreme poverty and strengthen the coalition for global partnership aligns with the current effort in development and global education to reach a wider global audience beyond the public in the Global North. This is reflected in the increasing profile of Southern perspectives in mainstream global education and development education journals, collaborative publications with academics in the Global South and the inclusion of the UN Sustainable Development Goals as an important theme in development and global education. Although such initiatives have opened the space for other perspectives in development and global education, foundational concepts such as 'poverty' and 'inequality' framed on dominant modernist and Eurocentric perceptions of the world and the 'other' have endured, or have only partially been subjected to critical interrogation.

Poverty and inequality are relative and highly contested terms, not only because they adopt different types of measurements, but are also because they are theorized broadly from two opposing schools of neoclassical and neo-Marxist perspectives (Goldberg and Pavcnik, 2004; Wei, 2015). Neoclassical theories explain inequality as a normal feature of economic growth and spatial inequality as the result of externalities associated with the clustering of economic activity around industrial locations (Kanbur and Venables, 2005). In contrast, the neo-Marxist approach explains inequality and disparity in development as a result of a core-periphery dependency relationship from a scalar perspective and mainly at the international level (Kanbur and Venables, 2005; Abdulai, 2014). In addition to the neoclassical convergence growth theory, it is also argued that spatial inequality results from the failure of national governments to adopt appropriate social policies and microeconomic measures in mitigating negative externalities (Sumner et al., 2012).

There is an orientation of development and global education social justice pedagogy towards the dependency core-periphery narrative that suggests the importance of developing robust methodological tools for analysing global poverty and the concept of spatial inequality. While a review of the extensive literature on the contrasting theories and models of inequality falls outside the scope of this article, much of the argument about spatial inequality is largely based on regional studies undertaken within a country using sub-national surveys (see Wei, 2000; Li and Wei, 2010; Stiglitz, 2012; Liao and Wei, 2015). These studies identified factors such as borders, 
location and agglomeration externalities as important determinants of economic activity and spatial inequality (Kanbur and Venables, 2005; Piketty, 2014; Abdulai, 2014).

Kanbur and Venables (2005) noted that spatial inequality in developing countries is due to the natural advantages of some regions relative to others and the presence of agglomeration forces leading to a clustering of activity. Berry et al. (2014: 390) noted that regional trade agreements such as 'the European free trade association (EFTA) and the North America Free Trade Agreement (NAFTA) promote convergence among member countries and regions leading to decline in trade with third countries'. At an international level, the NAFTA is an example of how geographical location and borders can impact on the manner in which countries are integrated or excluded from the globalized economy (Berry et al., 2014). This explanation can be replicated in understanding the advantages that countries such as Mexico have over other developing countries in Latin America. Landlocked countries that are distant from industrialized economies and that rely on the policies and goodwill of neighbours with coastline, are more vulnerable to multidimensional poverty than spatial inequality. This raises an argument made in this article that is often ignored in neoclassical trickle-down theory about disaggregating poverty dynamics from the concept of spatial inequality. Collier and Gunning (1999) also noted that in addition to economic volatility and lack of openness to international trade, the explanations for the low growth rate in African countries are found in geography and the landlocked nature of many countries.

Although development and global education is concerned with global dimensions of inequality, the neoclassical convergence argument on the spatiality of inequality derives country-level studies using sub-national data. For example, influential studies such as Liao and Wei (2015), Breau (2015) and Darling (2015), conducted across China, the United Kingdom and Canada respectively, were based on national surveys. These studies linked spatial inequality to the interaction between local and external factors such as urbanization and foreign direct Investment but reveal little on poverty levels and how spatial inequality may persist even with the decline in poverty. Although the influence of location, space and agglomeration on spatial inequality occurs across economies, development and global education is concerned primarily with the global pattern that manifests along a dependency relationship that is structural and historical (Sekhri, 2009).

The increased interconnectedness of the world through globalization suggests that the relationship between the industrial economies and less developed countries is conceived of as interdependent. Spatial inequality will therefore reflect the manner in which countries are integrated into the global production network defined by their political and economic proximity to the core. As an analytical paradigm concerned with the intersection of location and structure, intersectionality offers a critical tool for understanding how the globalization of production manifests in the concentration of poverty and inequality in patterns that reflect the core-periphery interdependence.

\section{The problem with measuring 'falling poverty' and country income classification}

The terms 'Global North' and 'Global South', 'developing' and 'less developed' countries are common metaphors used in distinguishing between the higherincome industrial economies and lower-income countries. Rather than connoting geographical locations, the terms are part of the development education lexicon used to conceptualize and describe economies by income group and their level of industrial and/or economic advancement. However, beyond the limitations of such a dichotomy, 
it is important to consider the pattern of concentration of poverty and inequality in the context of the arguments about the spatiality of inequality and the changing distribution of global poverty and inequality (Sumner et al., 2012).

There is a valid argument in the spatial inequality debate that suggests that most of the world's income-poor and multidimensional poor now live in countries classified as lower-middle-income economies that recently transitioned from the low-income group (Chandy and Gertz, 2011; Moss and Leo, 2011). This suggestion of a spatial distribution of poor people within and across countries is gaining rapid acceptance in development and global education discourse without critical engagement with the debates that shift attention from poor countries to poor people.

The penetration of global forces and the manner of integration of countries into the global economy, tends to lead to the increase of urban primacy and regional inequality across countries. Ironically, the World Bank classification of countries as lowincome, lower-middle income and upper-middle income is based on the resulting externalities (World Bank Data Team, 2016). The argument against constructing poverty and inequality in linear binaries is most compelling when it is considered that both conditions are found and reproduced in rich Global North and poor Global South countries. However, the concern of development and global education with the disproportionate concentration of spatial inequality and multidimensional poverty in countries on the margins of global interdependence requires that terms such as 'Global North' and 'Global South' are reconceptualized to reflect the current dynamics of a world more connected than ever before.

The major weakness in neoclassical growth theory is the assumption of equilibrium conditions of perfect markets, perfect information/knowledge flows, and free factor mobility. However, researchers of regional inequality and economic geography have challenged this assumption. For example, Rey and Sastré-Gutiérraz (2015) and Kanbur and Venables (2005) argue that country location and borders still have effects on regional inequality dynamics. These works also expose the weakness in the uncritical use of GDI per capita as an indicator of income distribution and poverty reduction and as the basis of proposing the transition of less developed economies from one income category to another.

The focus on the spatiality of inequality across economies tends to ignore the pattern in which poverty and inequality manifest and concentrate along the coreperiphery divide. The World Bank country income classifications are often used to argue for the emergence of a pattern where the extreme poor are now spatially distributed across low-income, lower-middle-income and upper-middle-income countries (Sumner, 2010). However, a notable feature in the World Bank country classification is that the three composite groups in mode of temporal transition belong outside the high-income industrialized countries referred to as 'core' or 'centre'. Ironically, the possibility of transitioning from and remaining in the lower- or upper-middleincome group depends on the manner in which the country is linked to the club of industrial economies and/or how it is positioned as an outsourcing intermediary in the globalization of production. The flaws in the World Bank GDI per capita income classification for analysing spatial distribution of poverty and inequality is discussed further in a later section.

However, as noted earlier, the countries listed as having a 'rising concentration of poor people, in spite of their transition from low-income and/or lower middle income to upper middle-income status' (Sumner et al., 2012: 5) are predominantly from the Global South (see Table 1). Post-colonial theory has been used in analysing how these countries share a historical legacy and how they are integrated into a globalized 
economy on the terms of industrialized countries as the 'subaltern' (Said, 1978; Spivak, 1988; Bhabha, 1994). Furthermore, many of the countries in the Global South that are grouped as undergoing transition from lower- to higher-middle-income economies are often countries rich in natural resources or minerals, such as Libya, Angola and Equatorial Guinea, with huge populations outside the formal foreign direct investment (FDI) economy.

While domestic economic policy is an important factor in the poverty and inequality debate, there are historical cultural and structural constraints that intersect with the globalization of production in reproducing spatial inequality across an interconnected core-periphery divide. Equatorial Guinea offers a classic example of the inadequacy of using estimates of gross national income (GNI) per capita derived from FDI and the formal economy in calculating income inequality and poverty levels, rather than using figures from the wider national workforce that also includes the informal sector.

The World Bank classify low-income economies as those with a GNI per capita of $\$ 1,025$ or less, the lower-middle income as those with a GNI between $\$ 1,026$ and $\$ 4,035$, and upper-middle income as those with a GNI between $\$ 4,036$ and $\$ 12,475$ (World Bank Data Team, 2016). Before its production of crude oil began in 1991, Equatorial Guinea was grouped among the poorest low-income countries, with a majority of the population employed in the agricultural sector as subsistence farmers. However, this status dramatically changed with the exploitation of crude oil, although only a fraction of the population were employed in this sector. Below is a list of countries with new income-group classification in 2016. Equatorial Guinea was reclassified from the high to the upper middle-income group in 2015.

Table 1: World Bank country income classification, 2016

\begin{tabular}{lll}
\hline Economy & Old group & New group \\
\hline Cambodia & Low & Lower middle \\
Equatorial Guinea & High & Upper middle \\
Georgia & Lower middle & Upper middle \\
Guyana & Lower middle & Upper middle \\
Mongolia & Upper middle & Lower middle \\
Russian Federation & High & Upper middle \\
Senegal & Lower middle & Low \\
Tonga & Upper middle & Lower middle \\
Tunisia & Upper middle & Lower middle \\
Venezuela, RB & High & Upper middle \\
\hline
\end{tabular}

Source: World Bank Data Team (2016)

With oil accounting for more than 60 per cent of GDP, a small population of 1.2 million and an official unemployment rate of 30 per cent, Equatorial Guinea made the uppermiddle-income category in 2016, having previously been classified as high income in 2015 (World Bank Data Team, 2016). However, a large segment of its population lives in conditions of deprivation similar to those in low-income countries. Additionally, the World Bank classification uses country population as a primary element in determining GNI per capita and purchasing power parity in measuring poverty and inequality. The size of the country, its proximity to the 'core' and the manner of integration into the global economy are critical factors that influence how countries such as Cuba, Ecuador, 
Dominica and Mexico are grouped or classified as transitioning from lower-middle to upper-income countries.

The implication for development and global education discourse, and the poverty and inequality debate is that such measurements rely on people employed in the higher paying oil and FDI investment sector and exclude the wider workforce in the agriculture and informal economy on the periphery. This illustration reinforces the earlier point about the dominant versus subordinate power relations in the global inequality debate, who decides what is considered knowledge and how poverty and spatial inequality are interpreted. The exclusion of populations that operate on the margins presents a major gap in the information used in deciding what and who, is included in measuring income inequality. Closing this gap requires a more inclusive paradigm for analysing the complex dynamics that sustain the current form of unjust interdependence. Intersectionality is proposed as an analytical paradigm that offers immense potential for understanding the complex interaction between structures, institutions and processes in reproducing poverty and inequality and their asymmetrical location across an interdependent world.

\section{Intersectionality: A paradigm for reconceptualizing dimensions of global poverty and inequality}

Intersectionality has evolved as a 'theoretical and methodological approach for understanding human experience of inequity as the outcome of the intersection and interaction of different social locations and institutions, rather than the result of single or distinct factors' (Hankivsky, 2014: 2-3). 'Social location' refers to social categories such as gender, race, ethnicity, religion and geography that are identity markers. The central proposition of intersectionality applied in this article is that privilege, oppression, exclusion and inclusion occur in the intersection of connected systems and structures of power that order and normalize how individuals and societies experience inequity.

The concept of intersectionality as originally developed by Kimberlé Crenshaw (1989) was applied mainly to research in gender studies and undertaken in a national context (Bilge and Denis, 2010). However, it has gained prominence as a paradigm, methodology and framework for analysing exclusion and privilege as shaped by the intersection of institutional systems operating within and across national boundaries (see, for example, Walby, 2009; Acker, 2006; Glenn, 2002; McCall, 2005). It has also evolved over time to include the analysis of social and institutional dynamics at transnational level. Within the context of this article, intersectionality is proposed as offering methodological tools for critically examining and understanding global poverty and inequality as the outcome of complex 'processes that are interactive, mutually complementary and historically co-determining' (Choo and Ferree, 2010: 2).

Considering the different ways in which intersectionality can be conceptualized in researching inequity, Choo and Ferree (Choo and Ferree, 2010: 13) propose the system-cored approach as appropriate for understanding the ways institutions interact in 'determining the organization of ownership, profit, and the commodification of labour' within and across jurisdictions. This approach, also referred to as systemic intersectionality, can be distinguished from the group-cored approach to intersectionality, which pays attention to the social location of predetermined groups and is applied in understanding inequality between social groups based on factors such as gender, race and religion (Bilge and Denis, 2010). The system-cored approach pays attention to understanding inequality from the interaction of institutional processes and therefore exposes how 'inequality spans and transforms structures at all levels and 
across diverse contexts' (Choo and Ferree, 2010: 13). It also highlights the interaction between local and international agencies, rather than social categories and does not consider any one process as primary. Systemic intersectionality is therefore interested in the intersection of 'mutually transformative processes' (Choo and Ferree, 2010: 12) and the normalization of inequity over time (Yuval-Davis, 2006).

Within the context of this article, therefore, system-cored intersectionality provides the lens for interrogating and reconceptualizing the construction of global inequality in the binary opposition of 'rich' and 'poor' countries. It also permits the analysis of the complex and intersecting dimensions of poverty, inequity and privilege and how inclusion and exclusion can be simultaneously experienced in the globalization of production.

Choo and Ferree (2010) suggest that the potential of intersectionality is best realized using a methodology that focuses on the dynamic interaction of institutions, rather than on the effects. However, the concern of development and global education with the international dimensions of inequality requires that attention is given to the interactive processes that result in the clustering of effects along particular patterns of power imbalances. Such a methodology also allows for a clearer understanding of the root causes of inequality, the pattern of distribution across geographies and the process by which it is sustained. The methodological implication of this approach is that it focuses on the way institutions interact in reproducing inequality and reconceptualizes the spatiality across core-periphery economies (Walby, 2009).

\section{The dualism of spatial inequality and the core-periphery binary: An intersectionality paradigm}

The terms 'global poverty' and 'inequality' are central themes that underpin related fields of global education, but whose dimensions are assumed and seldom critically interrogated. Quite often, the terms are used in development and global education literature to refer to persisting conditions of low productive capacity, low income and poor access to health and basic education. Although inequality is not synonymous with poverty and could actually increase in the midst of falling poverty levels, the urgent concern with reducing or eradicating extreme poverty usually overshadows discussions about the dimensions of inequality. The attention currently paid to growing inequality and its spatial distribution across high-income and low-income economies is arguably influenced by literature from the wider fields of development discussed earlier. This turn in the discourse is timely and desirable in understanding the distinction between the spatiality of inequality and the concentration of global poverty in particular regions of the world.

Although the process of globalization and the revolution in information and communication technology has altered the configuration of inequality across high- and low-income economies, there remains a disproportionate concentration of people living in poverty in developing countries (Sumner et al., 2012). It is this lopsided interdependence, and the dominance of the industrialized economies, that leads post-colonial theorists to make the distinction between countries at the centre that define how others are integrated and countries that operate on the margins (Odora Hoppers and Richard, 2012; Odora Hoppers, 2015; Baijnath and James, 2015). Intersectionality can be applied in exposing the problem of unequal power relations and the asymmetrical way in which the process of globalization intersects with institutions in defining the pattern of inequality that is reproduced and distributed across an interdependent and interconnected world. 
Within the theory and practice of development and global education, post-colonial theory has been used to analyse the multiple dimensions of power imbalances between the Global North and the Global South, and the implications that the marginalization of 'other' knowledge systems has on the production possibility frontier of the less industrialized countries (Spivak, 1988). However, the application of post-colonial theory in development and global education has focused mainly on power imbalances and how they define the relationship between the occidental and the subaltern other (Chen, 1995; Spivak, 1988). This resonates with the concern in development and global education with the widening gap in income and consumption levels between industrialized and less developed countries.

Although the dependency theory of the core-periphery binary is criticized for being too general in attempting to explain inequality and for omitting to consider context and related dynamics, intersectionality enables the reconceptualization of coreperiphery dependency from asymmetrical dependence to a complex interdependence that is social rather than geographical (Sekhri, 2009). There is also an acknowledgement of a core-periphery pattern in the disproportionate concentration of poverty in less industrialized economies (Bourguignon, 2016). This is further accelerated by the process of globalization and reflected in the way in which less developed countries are integrated into the global production system along a relationship of political economy with industrial economies at the core. The core-periphery structure in the globalization of production and a corresponding pattern in the concentration of poverty and inequality, suggests a dualism of spatial inequality and binaries in the distribution of global poverty. It is therefore important that development and global education adapts critical paradigms that interrogate and navigate the complex intersections and interactions between institutions and structures across the core-periphery divide.

In summary, intersectionality offers a paradigm for analysing globalization as enabling the intersection of processes in diverse locations rather than generating the configuration of inequalities, 'since every system is contingent and path dependent' (Choo and Ferree, 2010: 15). Intersectionality provides a methodology and paradigm for understanding how institutional processes operate and intersect at local and international levels in sustaining global poverty and inequality. It offers an analytical paradigm for understanding how the process of globalization intersects with imbalances in power relations in accelerating spatial inequality and in concentrating multidimensional poverty along a particular pattern that reflects unjust interdependence. Such an enlarged conceptualization of global poverty and inequality can enable a broad and holistic understanding of its dimensions and therefore offers a useful tool for transforming public perception, as well as for building the international coalitions that are necessary for achieving the UN Sustainable Development Goals.

\section{Conclusion}

While academics in development and global education embark on the worthy cause of expanding the audience and relevance of the field through interdisciplinary research, the uncritical promulgation of positions from related disciplines undermines values central to the social justice pedagogy of the field. This article has problematized the neoclassical interpretations of spatial inequality and its rejection of the coreperiphery dependency relationship between industrial and less-industrial economies (Tausch, 2010).

The main weaknesses of the dependency core-periphery theory are the views that industrial and less developed economies operate in binary opposition and the 
danger of generalization that undermines the experiences of individual countries. The concept of intersectionality was proposed as a holistic paradigm for reconceptualizing the core-periphery relation as interdependent rather than dependent. It therefore contributes to reframing the central themes of poverty and inequality that underpin the social justice pedagogy of development and global education. Specifically, the system approach to intersectionality was explored as an analytical tool that can enable an indepth and practical understanding of the dynamics of global poverty and inequality in the era of complex interdependent relationships within a globalized economy. It offers a paradigm for reconceptualizing the core-periphery dichotomy as an interdependent relationship in a more interconnected global economy.

I have argued that the absence of a strong theoretical foundation for the engagement of development and global education with poverty and inequality obscures the nuanced but important distinction between the two concepts. Such a distinction is important in understanding how spatial inequality and extreme poverty differ in the way they manifest and combine to define the productive capacity of global societies.

This article has noted that the argument about spatial inequality as a component of inequality relies mainly on studies undertaken at country level rather than trends across low- and high-income countries and therefore ignores the concentration of multidimensional poverty in a particular global pattern. Specifically, it has discussed the potential that intersectionality offers for fostering in-depth and practical understanding of the dynamics of global poverty, and the spatiality of inequality in a globalized economy. Drawing from the literature on spatial inequality, it has argued that the proximity of a country to industrialized countries (the core) and agglomeration externalities enable spill-over effects across neighbouring regions and are therefore key factors in the concentration of economic activity in particular patterns.

I have proposed that the argument for spatiality of inequality does not explain the dynamics that result in the disproportionate concentration of multidimensional poverty in the Global South. Indeed, it detracts from the fact that there can be a reduction in extreme poverty even in the midst of rising inequalities, as the processes that aggravate the two conditions may intersect, but are not synonymous. Therefore, inequality is not an adequate proxy for measuring levels of poverty, or for understanding the interaction of structure, processes and location in sustaining the current unjust form of global interdependence. The article concludes that theories of spatial inequality only partially explain how global poverty and inequality are reproduced within economies, but that they offer little to explain the way it is concentrated along particular global patterns that reflect the core-periphery interdependence.

\section{Notes on the contributor}

Son Gyoh is an independent researcher and a course facilitator in development education. After his MSc degree in development management, Son started a career in applied research and consultancy on the social inclusion of new migrant communities in Ireland. Son's field experience inspired him to undertake a PhD in development education at the UCL Institute of Education, London. His involvement in a United Nations Development Programme focal research programme in Nigeria influenced his growing interest in international development cooperation. 


\section{References}

Abdulai, A.-G. (2014) Rethinking Spatial Inequalities in Development: The primacy of politics and power relations (ESID Working Paper 29). Manchester: Effective States and Inclusive Development Research Centre.

Acker, J. (2006) 'Inequality regimes: Gender, class, and race in organizations'. Gender and Society, 20 (4), 441-64.

Baijnath, N. and James, G. (2015) 'Development priorities for African universities'. International Journal of Development Education and Global Learning, 7 (2), 61-74.

Berry, H., Guillén, M.F. and Hendi, A.S. (2014) 'Is there convergence across countries? A spatial approach'. Journal of International Business Studies, 45 (4), 387-404.

Bhabha, H.K. (1994) The Location of Culture. London: Routledge.

Bilge, S. and Denis, A. (2010) 'Introduction: Women, intersectionality and diasporas'. Journal of Intercultural Studies, 31 (1), 1-8.

Bourguignon, F. (2016) 'Inequality and globalization: How the rich get richer as the poor catch up'. Foreign Affairs, 95 (1), 11-15.

Bourn, D. (2015) The Theory and Practice of Development Education: A pedagogy for global social justice. London: Routledge.

Breau, S. (2015) 'Rising inequality in Canada: A regional perspective'. Applied Geography, 61, 58-69.

Chandy, L. and Gertz, G. (2011) Poverty in Numbers: The changing state of global poverty from 2005 to 2015 (Policy Brief 2011-01). Washington, DC: Brookings Institution.

Chen, X. (1995) Occidentalism: A theory of counter-discourse in post-Mao China. Oxford: Oxford University Press.

Choo, H.Y. and Ferree, M.M. (2010) 'Practicing intersectionality in sociological research: A critical analysis of inclusions, interactions, and institutions in the study of inequalities'. Sociological Theory, 28 (2), 129-49.

Collier, P. and Gunning, J.W. (1999) 'Why has Africa grown slowly?'. Journal of Economic Perspectives, 13 (3), 3-22.

Crenshaw, K. (1989) 'Demarginalizing the intersection of race and sex: A black feminist critique of antidiscrimination doctrine, feminist theory and antiracist politics'. University of Chicago Legal Forum, 139-67.

Denzin, N.K. and Lincoln, Y.S. (2000) 'Introduction: The discipline and practice of qualitative research'. In Denzin, N.K. and Lincoln, Y.S. (eds) Handbook of Qualitative Research. 2nd ed. Thousand Oaks, CA: SAGE Publications, 1-28.

Dorling, D. (2015) 'Income inequality in the UK: Comparison with five large Western European countries and the USA'. Applied Geography, 61, 24-34.

Glenn, E.N. (2002) Unequal Freedom: How race and gender shaped American citizenship and labor. Cambridge, MA: Harvard University Press.

Goldberg, P.K. and Pavcnik, N. (2004) Trade, Inequality, and Poverty: What do we know? Evidence from recent trade liberalization episodes in developing countries (NBER Working Paper 10593). Cambridge, MA: National Bureau of Economic Research.

Hankivsky, O. (2014) Intersectionality 101. Vancouver: Institute for Intersectionality Research and Policy.

Hartmeyer, H. and Wegimont, L. (eds) (2016) Global Education in Europe Revisited: Strategies and structures, policy, practice and challenges (Erziehungswissenschaft und Weltgesellschaft 9). Münster: Waxmann.

Ishii, Y. (2003) Development Education in Japan: A comparative analysis of the contexts for its emergence and its introduction into the Japanese school system. New York: RoutledgeFalmer.

Kanbur, R. and Sumner, A. (2011) Poor Countries or Poor People? Development assistance and the new geography of global poverty (Working Paper WP 2011-08). Ithaca, NY: Charles H. Dyson School of Applied Economics and Management.

Kanbur, R. and Venables, T. (2005) 'Introduction: Spatial inequality and development'. Journal of Economic Geography, 5 (1), 1-2.

Konttinen, P.N. and Vihriälä, A. (2014) Enhancing Southern Voices in Global Education. 2nd ed. Helsinki: Kepa ry. Online. www.globaalikasvatus.fi/sites/default/files/attachments/enhancingsouthern-voices-global-education_0.pdf (accessed 21 August 2018).

Li, Y. and Wei, Y.H.D. (2010) 'The spatial-temporal hierarchy of regional inequality of China'. Applied Geography, 30 (3), 303-16. 
Liao, F.H. and Wei, Y.D. (2015) 'Space, scale, and regional inequality in provincial China: A spatial filtering approach'. Applied Geography, 61, 94-104.

McCall, L. (2005) 'The complexity of intersectionality'. Signs: Journal of Women in Culture and Society, 30 (3), 1771-800.

Moss, T. and Leo, B. (2011) IDA at 65: Heading toward retirement or a fragile lease on life? (Working Paper 246). Washington, DC: Center for Global Development.

Odora Hoppers, C.A. (2015) 'Think Piece: Cognitive justice and integration without duress - The future of development education - Perspectives from the South'. International Journal of Development Education and Global Learning, 7 (2), 89-106.

Odora Hoppers, C.A. and Richards, H. (2012) Rethinking Thinking: Modernity's "other" and the transformation of the university. Pretoria: University of South Africa.

Piketty, T. (2014) Capital in the Twenty-First Century. Trans. Goldhammer, A. Cambridge, MA: Harvard University Press.

Rey, S.J. and Sastré Gutiérrez, M.L. (2015) 'Comparative spatial inequality dynamics: The case of Mexico and the United States'. Applied Geography, 61, 70-80.

Said, E.W. (1978) Orientalism: Western conceptions of the Orient. London: Routledge and Kegan Paul.

Sekhri, S. (2009) 'Dependency approach: Chances of survival in the 21st century'. African Journal of Political Science and International Relations, 3 (5), 242-52.

Spivak, G.C. (1988) 'Can the subaltern speak?' In Nelson, C. and Grossberg, L. (eds) Marxism and the Interpretation of Culture. Basingstoke: Macmillan, 271-314.

Stiglitz, J.E. (2012) The Price of Inequality. New York: W.W. Norton and Company.

Sumner, A. (2010) Global Poverty and the New Bottom Billion: What if three-quarters of the world's poor live in middle-income countries? (IDS Working Paper 349). Brighton: Institute of Development Studies.

Sumner, A., Suryahadi, A. and Thang, N. (2012) Poverty and Inequalities in Middle-Income Southeast Asia (Working Paper). Brighton: Institute of Development Studies.

Tausch, A. (2010) 'Globalisation and development: The relevance of classical "dependency" theory for the world today'. International Social Science Journal, 61 (202), 467-87.

Walby, S. (2009) Globalization and Inequalities: Complexity and contested modernities. London: SAGE Publications.

Wei, Y.D. (2000) Regional Development in China: States, globalization and inequality. London: Routledge.

Wei, Y.H.D. (2015) 'Network linkages and local embeddedness of foreign ventures in China: The case of Suzhou Municipality'. Regional Studies, 49 (2), 287-99.

World Bank Data Team (2016) 'New country classifications by income level: 2016-2017'. The DATA Blog, 1 July. Online. blogs.worldbank.org/opendata/new-country-classifications-2016 (accessed 25 February 2018).

Yuval-Davis, N. (2006) 'Intersectionality and feminist politics'. European Journal of Women's Studies, 13 (3), 193-209. 